\title{
Role of Colour Doppler Ultrasound in the Diagnosis and Grading of Liver Cirrhosis Compared with Transient Elastograpgy (Fibroscan)
}

E.M.Elshaer, H.M.Khater and A.F.Yousief

Radiology Dept., Faculty of Medicine, Benha Univ., Benha, Egypt

E-Mail: Enaam Elshaer@gmail.com

\begin{abstract}
The purpose of this study was to determine the morphological changes in hepatic vasculature and the flow hemodynamics in portal vein, hepatic veins and hepatic artery using various Doppler parameters in cirrhotic patients and to evaluate the variation in Doppler flow hemodynamics within cirrhotic livers as compared to liver stiffness measured by transient elastography. Study sample of 100 eligible patients with compensated liver cirrhosis were enrolled. All were examined with a pulsed Doppler flowmeter with a $3.75 \mathrm{MHz}$ convex and sector probe. Liver texture, splenic size, portal and splenic vein diameters, portal vein velocity, hepatic artery resistive index and waveform of the hepatic vein were evaluated in all subjects comparing results with liver stiffness measured by transient elastography. All the data were collected, tabulated and statistically analyzed using an IBM personal computer with Statistical Package of Social Science version 22. The mean age of the patients was found to be $51.8 \pm$ 10.2 years. The mean value of liver stiffness was $39.7 \pm 18.0 \mathrm{kPa}$. The echotexture of liver was coarse with irregular margin in 69 patients $(69.0 \%)$, coarse with smooth margin in 24 patients $(24.0 \%)$ and normal in 7 patients $(7.0 \%)$. The size of spleen was enlarged in $92.0 \%$ of patients. Portal vein diameter was enlarged in $66.0 \%$ of patients. Portal vein velocity shows abnormality in $65.0 \%$ of patients. Hepatic vein waveform in $7.0 \%$ of patients was triphasic and non-triphasic in $93.0 \%$. Hepatic artery restrictive index increased above normal range in $69.0 \%$ of patients. Splenic vein diameter was enlarged in $92.0 \%$. There were statistically highly significant relations ( $\mathrm{P}$ value $<0.001$ ) between liver stiffness measured by transient elastography and liver texture, hepatic vein waves in colour Doppler US. A highly significant negative correlation ( $\mathrm{P}$ value $<0.001)$ was found between Fibroscan results and portal vein velocity in our included cirrhotic patients. Fibroscan results had highly significant positive correlations ( $\mathrm{P}$ value $<0.001$ ) with splenic size, portal vein diameter, HARI and splenic vein diameter. Colour Doppler US play an important role in the diagnosis of the morphological changes in hepatic vasculature and the flow hemodynamics in portal vein, hepatic veins and hepatic artery. Fibroscan could predict changes in intrahepatic vascular resistance and it improves the accuracy of Doppler US in the detection of cirrhosis.
\end{abstract}

Key words: Liver cirrhosis, Doppler, Hepatic vein, portal vein, Hepatic artery, Fibroscan.

\section{Introduction}

Sonography is at present those The majority made technique for finding and catch up of incessant viral hepatitis. It may be supportive in the analysis Also catch up for patients who bring excellent discoveries about cirque What's more portal hypertension. However, b mode sonography may be unable for looking at cases with ordinary liver echogenicity Also without At whatever portal hypertension discoveries [1]. Doppler sonography will be a noninvasive symptomatic modality In light of hemodynamic parameters that could need created Significantly over instances with typical discoveries around $b$ mode sonography. Therefore, appraisal of these alterations need essentialness to promptly finding Furthermore to close catch up for formerly diagnosed situations [2]. Transient Elastography is An noninvasive technique recommended for those appraisal about liver fibrosis On patients with incessant liver sicknesses Eventually Tom's perusing measuring liver firmness [3]. Liver firmness measured Toward te deum essentially associate for the youngster Pugh score and for clinical parameters (past historical backdrop of dying varices, ascites Furthermore HCC), living parameters (platelets, prothrombin time, figure $\mathrm{V}$, egg whites What's more bilirubin) and different important parameters (esophageal varices Furthermore splenomegaly with respect to ultrasonography) for liver infection seriousness [4]. With the goal assessment of the variety Previously, doppler stream hemodynamics in the hepatic portal, blood vessel Also systemic dissemination inside cirrhotic livers Concerning illustration contrasted with LS measured Eventually Tom's perusing te deum might help On giving work to extra data with exceptional get it the watched progressions in hepatic hemodynamics for progression for liver cirque.

\section{Patients \& methods}

This was a prospective cohort study recruiting 100 consecutive adult compensated cirrhotic patients from National Liver Institute, Menoufia University. Patients were enrolled from October 2017 to February 2019. Informed consent was obtained from all participants and thorough history taking was 
obtained. Each subject was examined after overnight fasting in supine position after a rest of $15 \mathrm{~min}$ to avoid any influence of food, posture and exercise. Liver texture, spleen size, portal and splenic vein diameters, portal vein velocity, hepatic artery resistive index and waveform of the hepatic vein were evaluated in all subjects.

All measurements were done by a single radiologist using a pulsed Doppler flowmeter with a 3.75 MHz convex and sector probe. The instrument is equipped with software to calculate the timeaveraged velocity from the velocity spectral display after placement of the calipers. The sample width was selected to cover almost entire vessel diameter. Pulse repetition frequency was adjusted so as not to surpass the limit of the displayed maximum velocity. The angle of insonation was always maintained $<60$. Internal diameter of the vessels was measured manually from the B mode images [5].

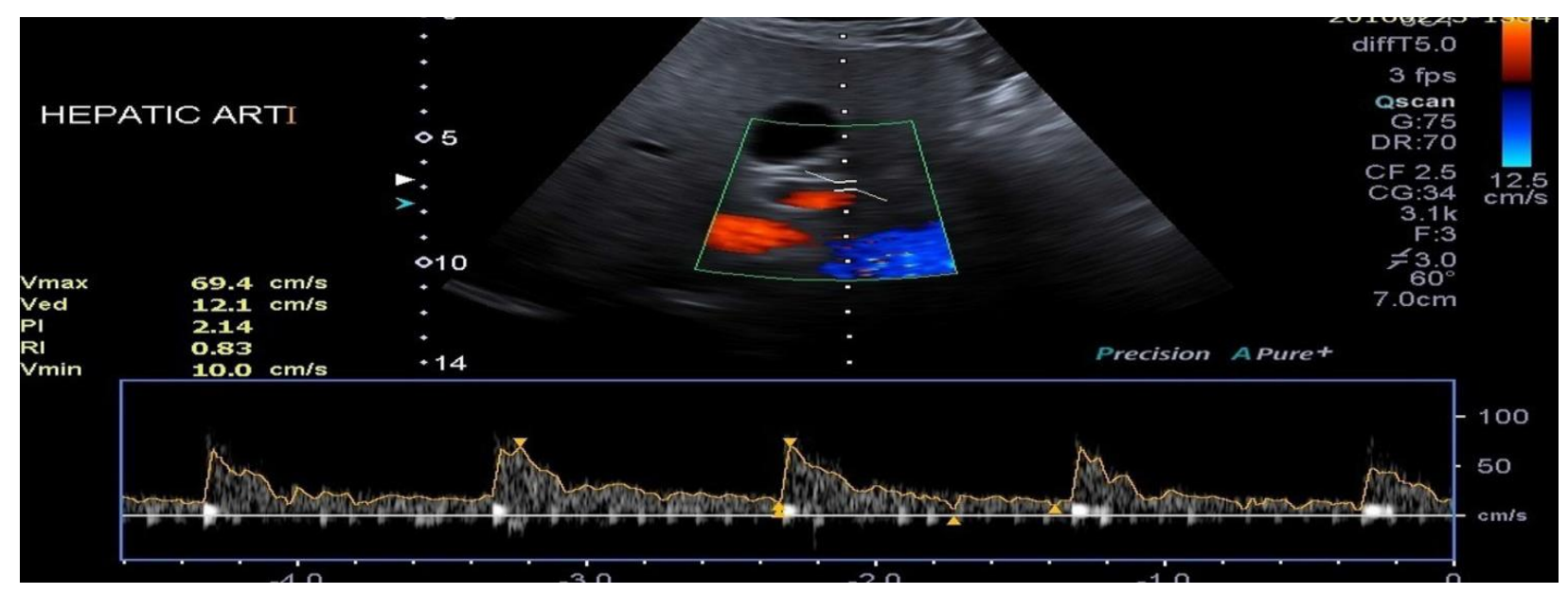

Fig (1) Doppler ultrasound measurements of hepatic artery.

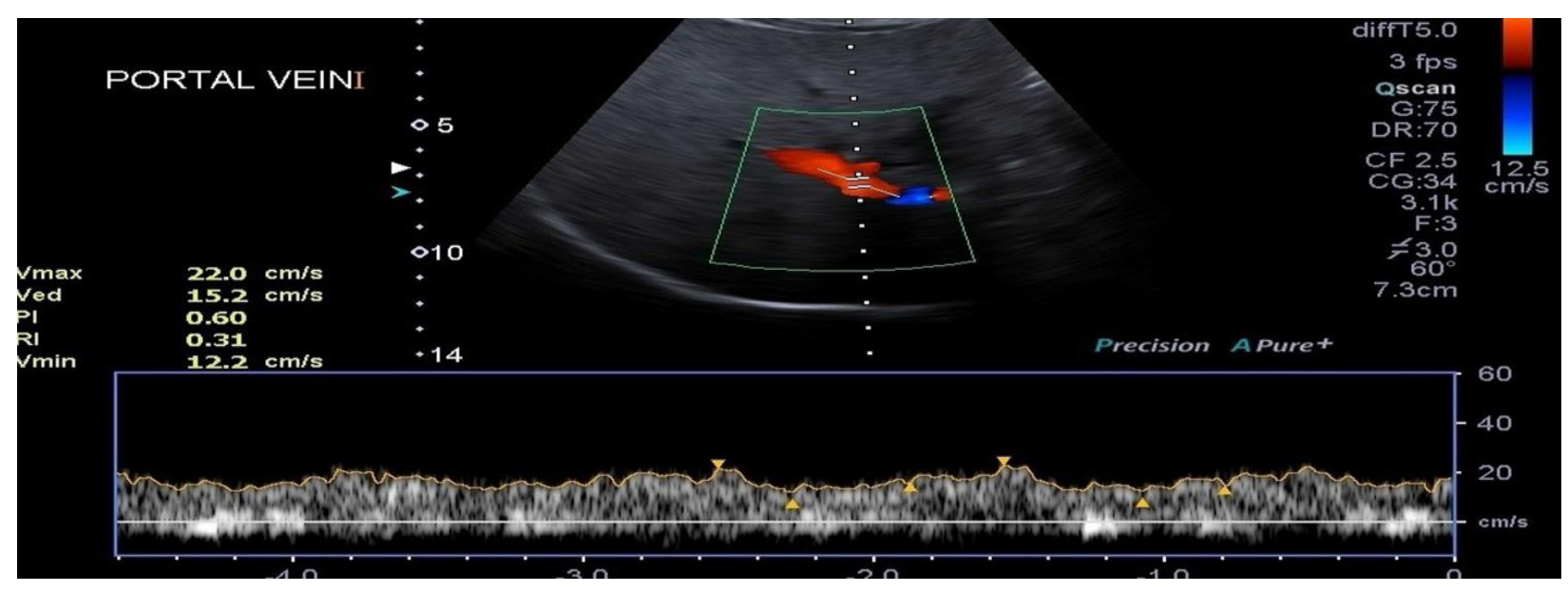

Fig (2) Doppler ultrasound measurements of portal vein.

A single operator performed all FibroScan examinations according to the manufacturer's protocol with the patient lying in the dorsal decubitus position and the tip of the transducer probe was placed on the skin between the ribs over the right lobe of the liver. Liver stiffness assessment was performed on a FibroScan 502 Touch (Echosen, Paris, France). A reliable liver stiffness result was defined as at least 10 valid shots, a success rate of at least $60 \%$, and an interquartile range that was $<30 \%$ of the median value. The results were considered unreliable if these criteria were not met (6). 


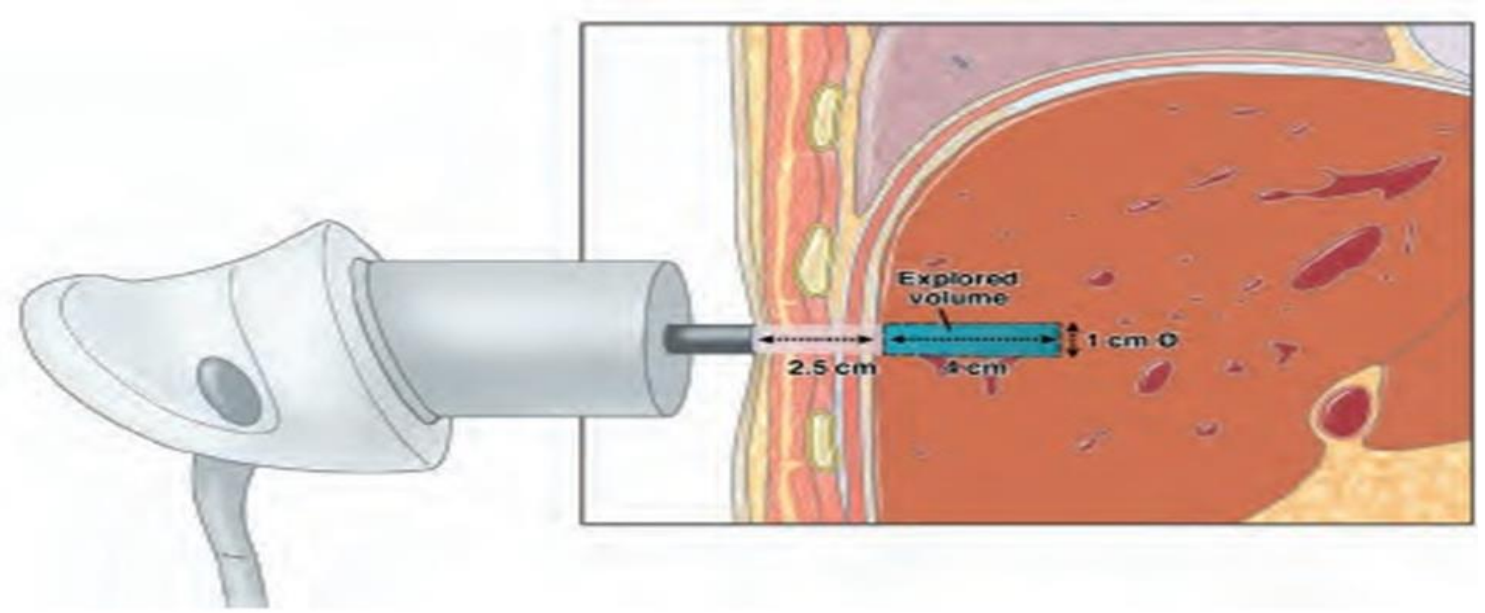

Fig (3) Liver stiffness measurement using FibroScan.

All the data were collected, tabulated and statistically analyzed using an IBM personal computer with Statistical Package of Social Science version 22.

\section{Results}

In our current prospective study, a total of 100 cirrhotic patients (68 males \& 32 females) who underwent pelviabdominal ultrasound with hepatic Doppler and TE measured by Fibroscan were recruited. The average age was $51.8 \pm 10.2$ years. Liver texture was coarse with irregular margin in $69.0 \%$, coarse with smooth margin in $24.0 \%$ and normal in $7.0 \%$ of patients. In ours, the mean value of splenic size was $17 \pm 3.16 \mathrm{~cm}$ and the size of spleen was enlarged in $92.0 \%$ of patients. As regard splenic vein diameter, the mean value was $14.3 \pm$ $3.68 \mathrm{~mm}$ and diameter was increased above normal level in $92.0 \%$ of patients.

Furthermore, we observed that the mean value of portal vein diameter was $14.2 \pm 3.58 \mathrm{~mm}$ and portal vein diameter was enlarged in $66.0 \%$ of patients. As regard portal vein velocity, the mean value was 11.4 $\pm 3.25 \mathrm{~cm} / \mathrm{sec}$ and portal vein velocity decreased below normal range in $65.0 \%$ of patients.

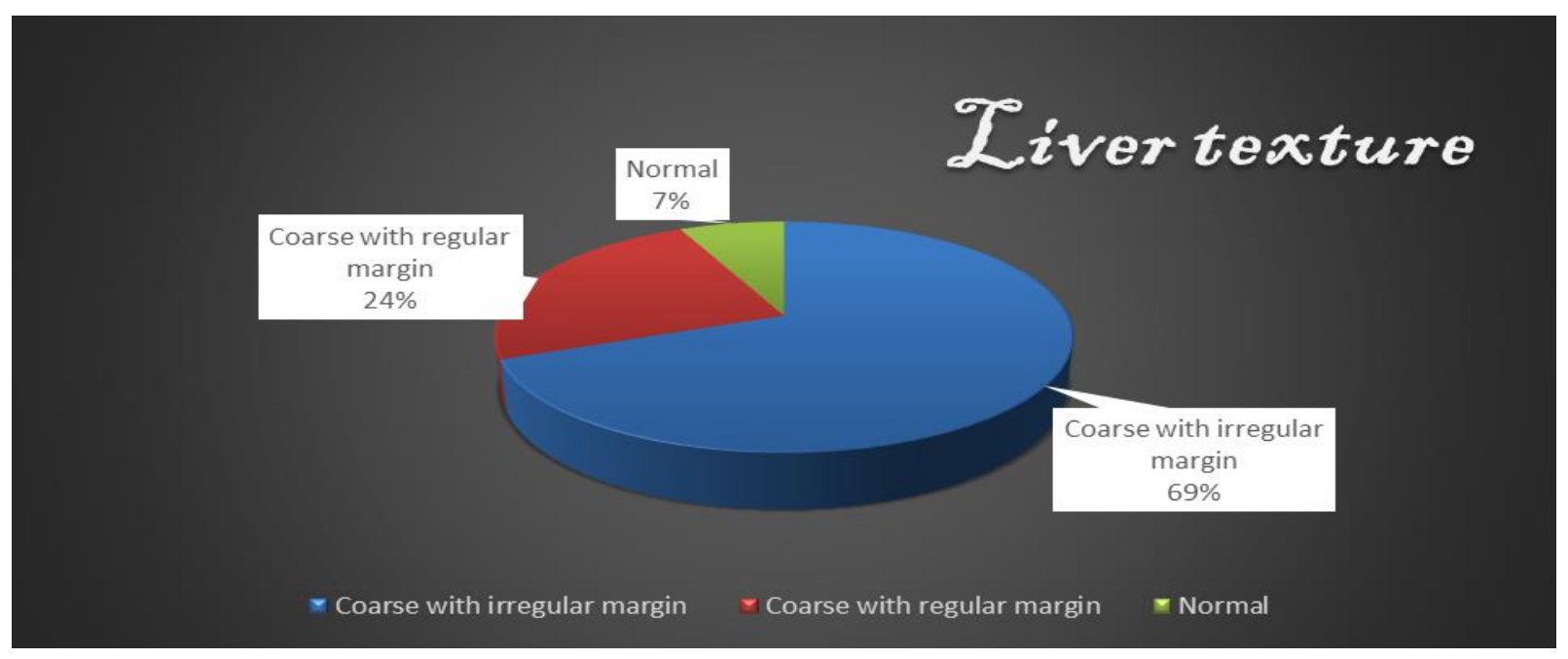

Fig (4) Liver texture among the studied group. 


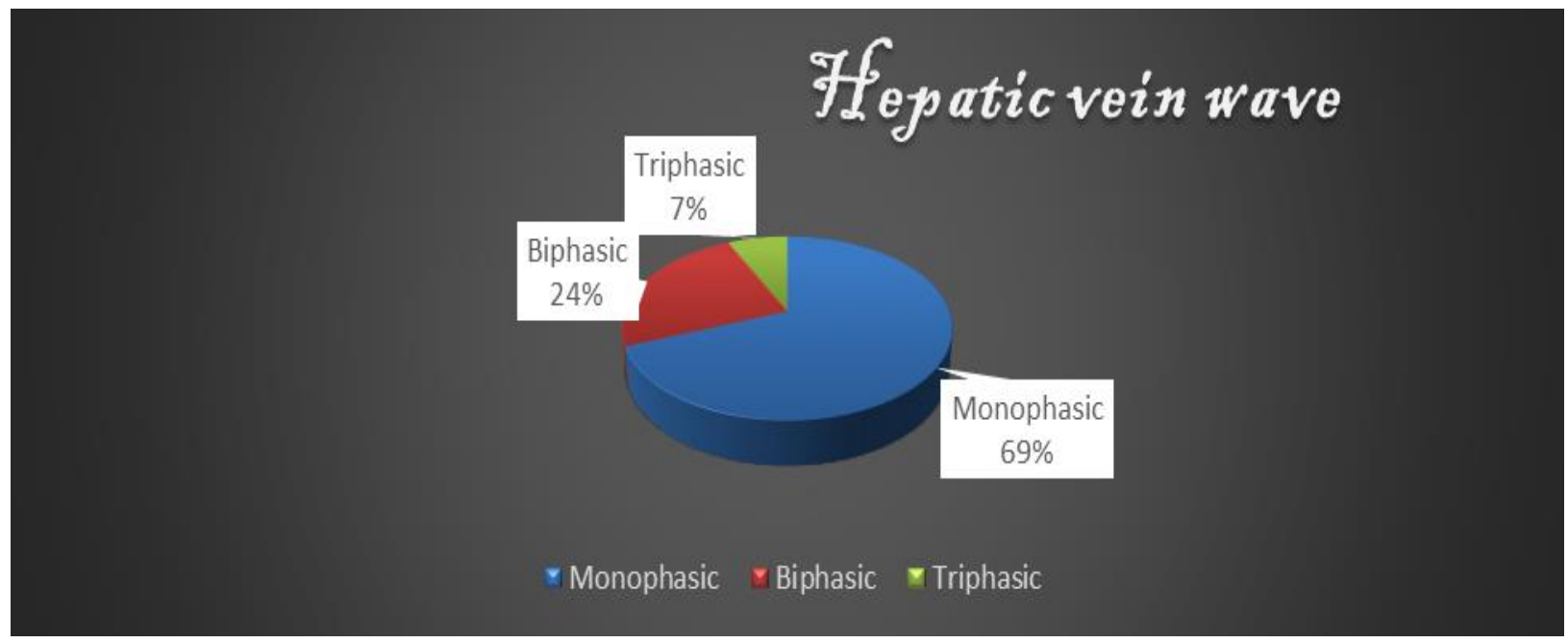

Fig (5) Hepatic vein wave among the studied group.

Also, we observed that hepatic vein wave was triphasic in $7.0 \%$ and non triphasic in $93.0 \%$ of patients. The mean value of HARI was $0.78 \pm 0.1$ and HARI increased above normal range in $69.0 \%$ of patients. Finally, the mean value of TE measured by Fibroscan was $39.7 \pm 18 \mathrm{kPa}$ with the range from 17.6 to $75 \mathrm{kPa}$.

Table (1) The demographic data, Doppler, and Transient Elastography findings.

\begin{tabular}{lc}
\hline Variables & Studied group \\
\hline Age, years (Mean \pm SD) & $51.8 \pm 10.2$ \\
Fibroscan level, kPa (Mean \pm SD) & $39.7 \pm 18$ \\
Splenic size, cm (Mean \pm SD) & $17 \pm 3.16$ \\
Splenic vein diameter, mm (Mean \pm SD) & $14.3 \pm 3.68$ \\
Portal vein diameter, mm (Mean \pm SD) & $14.2 \pm 3.58$ \\
Portal vein velocity, cm/sec (Mean \pm SD) & $11.4 \pm 3.25$ \\
HARI (Mean \pm SD) & $0.78 \pm 0.1$ \\
\hline
\end{tabular}

In our prospective work, we concluded that there were statistically highly significant relations ( $\mathrm{P}$ value $<0.001$ ) between liver stiffness measured by Fibroscan and liver texture, hepatic vein waves in colour Doppler US. A highly significant negative correlation ( $\mathrm{P}$ value $<0.001)$ was found between
Fibroscan results and portal vein velocity in our included cirrhotic patients. Fibroscan results had highly significant positive correlations ( $\mathrm{P}$ value < 0.001) with splenic size, portal vein diameter, HARI and splenic vein diameter.

Table (2) Correlations between Fibroscan results and different parameters.

\begin{tabular}{lcc}
\hline Variables & Fibroscan results $(\mathbf{k P a})$ \\
\hline & $\mathbf{r}$ & P value \\
Spleen size $(\mathbf{c m})$ & 0.378 & $<0.001(\mathrm{HS})$ \\
Portal vein diameter $(\mathbf{m m})$ & 0.732 & $<0.001(\mathrm{HS})$ \\
Portal vein velocity $(\mathbf{c m} / \mathbf{s e c})$ & -0.794 & $<0.001(\mathrm{HS})$ \\
Hepatic artery resistive index $($ HARI) & 0.597 & $<0.001(\mathrm{HS})$ \\
Splenic vein diameter $(\mathbf{m m})$ & 0.619 & $<0.001(\mathrm{HS})$ \\
\hline
\end{tabular}


Table (3) Relations between Fibroscan results and liver texture \& hepatic vein waves.

\begin{tabular}{lcccc}
\hline Variables & Fibroscan (kPa) & $\begin{array}{c}\text { Test of } \\
\text { Mean } \pm \text { SD }\end{array}$ & P value \\
\hline & Normal $(\mathrm{N}=7)$ & $18.6 \pm 0.71$ & & \\
& Coarse with smooth margin $(\mathrm{N}=24)$ & $22.9 \pm 3.9$ & $\mathrm{~K}=61.4$ & $<0.001$ (HS) \\
Coarse with irregular margin & $47.7 \pm 16$ & & \\
Liver texture & $(\mathrm{N}=69)$ & & & \\
Hepatic vein & Monophasic $(\mathrm{N}=69)$ & $47.7 \pm 16$ & & \\
waves & Biphasic $(\mathrm{N}=24)$ & $22.9 \pm 3.9$ & $\mathrm{~K}=61.4$ & $<0.001$ (HS) \\
\hline
\end{tabular}

\section{Discussion}

HCV spoiling is a standout amongst the principle reason for Ceaseless liver infection overall. The long haul hepatic sway about HCV spoiling is profoundly variable, starting with negligible transforms will Ceaseless hepatitis, broad fibrosis What's more cirque for or without HCC. Raised vascular imperviousness and expanded portal blood inflow need aid two vital components that bring been showed up for a chance to be included in the improvement from claiming portal hypertension optional should cirque [7].

Schedule us assessment could identify those improvement for portal hypertension, HCC and other difficulties about cirque. Doppler us assumes a paramount part in the consider of portal vein, hepatic course Furthermore hepatic veins Furthermore camwood affirm their patency Also stream course. Variety clinched alongside hepatic hemodynamics showed done liver cirque need been demonstrated done past investigations to associate with the seriousness about cirque. However, the degree of transforms On doppler us stream parameters done foreseeing the seriousness from claiming liver cirque stays vague [1].

Acknowledging the test contentions supporting the theory that doppler us is a advantageous supplement On assessing the hemodynamic progressions seen inside An cirrhotic liver, the grade point from claiming this contemplate might have been will figure out the morphologic progressions clinched alongside hepatic vasculature and the stream hemodynamics for portal vein, hepatic veins What's more hepatic course utilizing Different doppler parameters over instances of cirque.

Analyzed 160 patients for portal hypertension Furthermore dilatation of the portal vein might have been distinguished done 73 for 129 patients, dilatation of the splenic vein done $70 \%$ of patients and likewise showed vanishing for ordinary gauge variety (>20\%) Throughout breath Previously, splenic alternately predominant mesenteric veins [8]. Arranged waveform qualities from claiming hepatic veins under 3 groups, HV0, HV1, What's more HV2. Around cirrhotic patients, HV0 might have been discovered over (50\%), HV1 in (32\%) What's more HV2 Previously, 11(18\%). Along these lines acknowledging those HV0 example Similarly as the typical doppler waveform, abnormalities in the waveform about hepatic veins, struck them for half from claiming cirrhotic patients [9].

Vassiliades et al., performed doppler sonography Previously, 43 patients for diffuse liver infection will determine HARI. It went from 0. $64 \pm 0.06$ done patients with promptly cirque on $0.68 \pm 0.09$ to patients with extreme aggravation. They were unabated on show whatever connection between the HARI worth and the level of hepatic pathology [10]. In An investigation carried accentuated that portal blood stream speed declines On portal hypertension What's more it might have been $9.38 \mathrm{~cm} / \mathrm{sec}$ Also inferred that diminish from claiming portal blood stream speed underneath $12 \mathrm{~cm} / \mathrm{sec}$ is a dependable pointer of the portal hypertension [11].

Ahead their examine ahead 35 patients for clinical analysis of cirque recorded that dilatation of the portal trunk might have been discovered for 20 patients, dilatation of the splenic vein might have been watched for $63 \%$ about patients. The Normal quality for portal blood stream speed might have been discovered will make $12.56 \pm 0.11 \mathrm{~cm} / \mathrm{sec}$. They recorded abnormal hepatic vein waveform Previously, 17 patients. Diminished plentifulness of the phasic oscillations (HV1 pattern) might have been watched to 10 patients same time totally even waveform without At whatever phasic swaying (HV2 pattern) might have been exhibited for 7 patients. Whatever is left 18 patients indicated typical triphasic waveforms (HV0 pattern). Those imply HARI might have been found should be $0.74 \pm 0.11$ [12] .

Looking into their study test for 56 qualified patients with liver cirque watched that decreased portal vein speed might have been seen for a mean quality from claiming $13.9 \mathrm{~cm} / \mathrm{s}$ in cirrhotic patients Also it declines Similarly as seriousness from claiming cirque worsens. HV ghastly waveform might have been also exhibited to be modified in cirrhotic patients. Eleven (19.6\%) of the 56 patients showed smoothed HV doppler ghastly waveform. 
They need also found that the frequency about hosing from claiming $\mathrm{HV}$ waveforms correlates with the seriousness for cirrhosis, Furthermore Likewise there is more excellent probability of watching hepatic venous outpouring hindrance over higher evaluation cirque. They finished up that HARI might have been essentially higher clinched alongside cirque [13].

Done our current prospective study, what added up to 100 cirrhotic patients (68 guys \& 32 females) who underwent pelviabdominal ultrasonography with hepatic doppler and LS measured Toward Fibroscan were recruited. Those Normal agdistis might have been $51.8 \pm 10.2$ a considerable length of time. Liver composition might have been coarse with unpredictable edge On $69.0 \%$, coarse with smooth birch edge On 24. $0 \%$ Also typical On 7. $0 \%$ for patients, separately. To ours, those mean quality for splenic size might have been $17 \pm 3.16 \mathrm{~cm}$ and the span for spleen might have been extended in $92.0 \%$ of patients. Likewise respect splenic vein diameter, those mean quality might have been $14.3 \pm 3.68 \mathrm{~mm}$ What's more breadth might have been expanded over typical level done $92.0 \%$ of patients. Furthermore, we watched that those mean quality for portal vein breadth might have been $14.2 \pm 3.58 \mathrm{~mm}$ and portal vein breadth might have been extended in $66.0 \%$ of patients. Likewise respect portal vein velocity, the mean quality might have been $11.4 \pm 3.25 \mathrm{~cm} / \mathrm{sec}$ What's more portal vein speed diminished The following ordinary run in $65.0 \%$ for patients.

Finally, we watched that hepatic vein wave might have been triphasic done 7. $0 \%$ from claiming patients Also non triphasic Previously, 93. $0 \%$. The wonder need been attributed to expanded parenchymal firmness impairing HV compliance, thereby bringing about those misfortune of HV phasicity (14). Those mean quality about HARI might have been $0.78 \pm 0.1$ What's more HARI expanded over ordinary run in $69.0 \%$ from claiming patients. Sacerdoti et al. , stated that those hepatic blood vessel safety over cirque Might a chance to be modified through those same instruments that were answerable for those expansion Previously, portal resistance, i. E. Twisting from claiming hepatic building design created Eventually Tom's perusing cirrhosis, decrease from claiming vascular space Also different even now undefined variables [15].

Liver firmness measured Toward FibroScan, is An noninvasive technique suggested to those evaluation for liver fibrosis in patients for constant liver ailments. Te deum measures LS over a volume that approximates An barrel from claiming $1 \mathrm{~cm}$ totally Also $4 \mathrm{~cm}$ long, between 25 Furthermore 65 $\mathrm{mm}$ beneath skin surface. This volume is in any event 100 times greater over An biopsy test and may be thusly distant that's only the tip of the iceberg illustrative of the hepatic parenchyma (16). So, those second point from claiming this prospective investigation might have been will assess those variety over doppler stream hemodynamics in the hepatic portal, blood vessel What's more systemic dissemination inside cirrhotic livers Similarly as contrasted with LS measured Toward te deum.

We watched that those mean quality for te deum measured Eventually Tom's perusing Fibroscan in the concentrated on gathering might have been $39.7 \pm 18$ $\mathrm{kPa}$ for the reach starting with 17.6 with $75 \mathrm{kPa}$.

Examine the symptomatic noteworthiness for te deum in An Every day schedule clinical setting in examination ultrasonography Eventually Tom's perusing assessment about 291 successive patients for constant liver infection about Different aetiologies and watched that affectability of te deum for the identification of liver cirque might have been 90. $4 \%$, contrasted with $80.1 \%$ for ultrasonography Furthermore that consolidation of te deum with ultrasonography expanded affectability to $96.1 \%$ (17). Highlighted examination of doppler ultrasonography and te deum in the finding for critical fibrosis Previously, their ponder around 63 patients Furthermore inferred that doppler us need direct affectability and specificity, which is easier compared for te deum to those finding of huge fibrosis. However, it might a chance to be utilized as an elective system to the appraisal from claiming fibrosis done patients who need aid not handy hopefuls for te deum assessment [18].

Clinched alongside their investigation once 102 patients for unending liver infection for Different etiology, affirmed that doppler parameters alone foresee the vicinity for critical fibrosis for reasonable exactness. Superior prediction rates are attained Eventually Tom's perusing joining together doppler variables with LS by te deum [19]. To their study around 514 patients for constant liver infection affirmed that Elastography enhances the exactness for Doppler-US in the identification from claiming extreme fibrosis [20].

Clinched alongside our prospective work, we finished up that there were statistically Exceedingly huge relations $(\mathrm{P}$ worth $<0$. 001) the middle of LS measured Toward te deum What's more liver texture, hepatic vein waves On color doppler us. A profoundly noteworthy negative correspondence (P esteem < 0. 001) might have been discovered the middle of Fibroscan effects and portal vein speed over our incorporated cirrhotic patients. Fibroscan outcomes needed Exceptionally noteworthy certain correlations (P quality < 0. 001) for splenic size, portal vein diameter, HARI Also splenic vein breadth. 


\section{Conclusion}

In conclusion, alterations of liver hemodynamics resulting from inflammation at the tissue level are detectable in Doppler sonography and LS measured by TE could predict changes in intrahepatic vascular resistance and it improves the accuracy of Doppler US in the detection of cirrhosis.

\subsection{Conflict of interest}

The authors declare that they have no conflict of interest.

\section{References}

[1] K.Shateri, A.Mohammadi, F.Moloudi, E.Nosair and M.Ghasemi-rad, Correlation Between Sonographic Portal Vein Diameter and Flow Velocity With the Clinical Scoring Systems MELD and CTP in Cirrhotic Patients: Is There a Relationship? Gastroenterology Research, Vol.5,pp.112-119,2012.

[2] M.B.Thomas, D.Jaffe, M.M.Choti， J.Belghiti, S.Curley, Y.Fong, G.Gores, R. Kerlan, R.Merle, R.Poon, L.Schwatz, M.Mooney and A.Venook, Hepatocellular carcinoma: consensus recommendations of the National Cancer Institute Clinical Trials Planning Meeting. Journal of Clinical Oncology, Vol.28,pp.3994-4005,2010.

[3] L.Castera, X.Forns and A.Albert, Non-invasive evaluation of liver fibrosis using Transient Elastography. Journal of Hepatology, Vol.48,pp.835-847,2008.

[4] V.de Lédinghen and J.Vergniol, Transient Elastography for the diagnosis of liver fibrosis. Expert Review of Medical Devices, Vol.7,pp.811823,2010 .

[5] D.Strobel, K.Seitz, W.Blank, A.Schuler, C.Dietrich, R.Muratori, A.von Herbay and G.Donati, Contrast-enhanced ultrasound for the characterization of focal liver lesions diagnostic accuracy in clinical practice (DEGUM multicenter trial). Ultraschall Med, Vol.29,pp.499-505,2008.

[6] D.Lucidarme, J.Foucher, J.Le Bail Vergniol, L.Castera，C.Duburque，G. Forzy , B.Filoche , P.Couzigou and V.de Lédinghen, Factors of accuracy of Transient Elastography (FibroScan) for the diagnosis of liver fibrosis in chronic hepatitis C. Journal of Hepatology, Vol.49,pp.1083-1089,2009.

[7] European Association for the Study of the Liver. EASL clinical practice guidelines: Management of hepatitis C virus infection. Journal of Hepatology, vol.55,pp.245-264,2011.

[8] L. Bolondi, A. Mazziotti, V. Arienti, G. Gasbarrini, A. Cavallari, L. Possati and G. Labò, Ultrasonographic study of portal venous system in portal hypertension and after portosystemic shunt operation. Surgery, Vol.95,pp.261-269,1984.

[9] L.Bolondi, S.LiBaasi, S.Gaiani, G.Zironi, G.Benzi, V.Santi and L.Barbara Liver cirrhosis, Changes of Doppler waveform of hepatic veins. Radiology, vol.178,pp.513-516,1991.

[10] V.G.Vassiliades, T.D.Ostrow, J.L.Chezmar, G.L.Hertzler and R.C.Nelson, Hepatic arterial resistive indices: correlation with the severity of cirrhosis. Abdom Imaging, Vol.18,pp.61-65,1993.

[11] D.Tomic, R.Jesic, V.Krstic Arienti and F.Moloudi, Drop of the portal blood flow: An important sign of the portal hypertension. Arch Gastroenterohepatol, Vol.20,pp.89-92,2001.

[12] K.Ahmad, S.K.Khanna, A.Sundas, R.K.Rauniyar, R.Koirala and M.K.Gupta, Duplex Sonographic Evaluation of Hepatic Vasculature in Cirrhosis. Nepal Journal of Medical Sciences, Vol.2,pp.13-19,2013.

[13] A.M.Afif, J.P.Chang, Y.Y.Wang, S.D.Lau, F.Deng, S.Y.Goh, M.K.Pwint, C.C.Ooi, N.Venkatanarasimha and A.Lo RH, sonographic Doppler study of the hepatic vein, portal vein and hepatic artery in liver cirrhosis: Correlation of hepatic hemodynamics with clinical Child Pugh score in Singapore. Ultrasound, Vol.25,pp.213221,2017.

[14] D. Zekanovic, N.Ljubicic, M.Boban, M.Nikolic, D.Delic-Brkljacic, P. Gacina, I .Klarin and J.Turcinov, Doppler ultrasound of hepatic and system hemodynamics in patients with alcoholic liver cirrhosis. Dig Dis Sci, Vol.55, pp.458466,2010.

[15] D.Sacerdoti, C.Merkel, M.Bolognesi, P.Amodio, P.Angeli , A.Gatta, Hepatic arterial resistance in cirrhosis with and without portal vein thrombosis: relationship with portal hemodynamics. Gastroenterolgy, Vol.108,pp.1152-1158. ,1995.

[16] P.Ingiliz, K.P.Chhay, M.Munteanu, P.Lebray , Y.Ngo , D.Roulot , Y .Benhamou , D.Thabut , V.Ratziu and T.Poynard , Applicability and variability of liver stiffness measurements according to probe position. World Journal of Gastroenterology, Vol.15, pp.33983404,2009 .

[17] T.Göbel, J.Schadewaldt-Tümmers, L.Greiner, C.Poremba, D.Häussinger and A.Erhardt, Transient elastography improves detection of liver cirrhosis compared to routine screening tests. World J Gastroenterol, Vol.21,pp.953-960, 2015.

[18] R.Ergelen, Y.Yilmaz, R.Asedov, C.Celikel, H.Akin, O.Bugdayci, E.Altun and D.Tuney, Comparison of Doppler ultrasound and transient elastography in the diagnosis of significant 
fibrosis in patients with nonalcoholic steatohepatitis. Abdom Radiol (NY), Vol.41,pp.1505-1510,2016.

[19] T.Alempijevic, S.Zec, V.Nikolic, A.Veljkovic, Z.Stojanovic, V.Matovic and T. Milosavljevic, Doppler ultrasonography combined with transient elastography improves the noninvasive assessment of fibrosis in patients with chronic liver diseases. Med Ultrason, Vol.19,pp.7$15,2017$.

[20] J.Delahaye, P.Bazeries, A.Lannes, J.Lebigot, V.Cartier, F.Oberti, I.Fouchard Hubert, A.Paisant, S.Michalak-Provost, M.C.Rousselet, P.Cales, J.Boursier and C.Aubé, Doppler ultrasonography devices, including elastography, allow for accurate diagnosis of severe liver fibrosis. Eur J Radiol, vol.108,pp.133-139,2018. 